\title{
PHÂN TÍCH THÀNH PHẦN, TÍNH CHẤT SẢN PHẨM KHÍ VÀ CONDENSATE MỎ THIÊN UNG
}

\author{
Nguyễn Bá Khoa, Nguyễn Huỳnh Anh, Nguyễn Phan Trí, Nguyễn Thị Anh Thư, Nguyễn Hiền Phong, Nguyễn Xuân Hợp, Ngô Thị Loan \\ Lương Thị Hồng Hải, Nguyễn Văn Lam, Nguyễn Thanh Tùng, Nguyễn Văn Hùng, Trương Hữu Đăng Khôi \\ Viên Dầu khí Việt Nam \\ Email: anhnguyenh@vpi.pvn.vn \\ https://doi.org/10.47800/PVJ.2021.08-02
}

\section{Tóm tắt}

Bài báo giới thiệu kết quả phân tích thành phần, tính chất mẫu khí và condensate mỏ Thiên Ưng, so sánh với tính chất sản phẩm khí và condensate khác tại Việt Nam. Khí tự nhiên mỏ Thiên Ưng có thành phần chủ yếu là methane với hàm lượng dao động từ 75,231 - 76,402 \%mol. Tổng các thành phần hydrocarbon còn lại trong khí mỏ Thiên Ưng chiếm từ 7,083 - 7,123 \%mol, trong đó hàm lượng hydrocarbon lỏng $\left(\mathrm{C}_{6}+\right)$ rất thấp, từ 0,172 - 0,226\%mol. Khí mỏ Thiên Ưng là khí ngọt, có hàm lượng $\mathrm{H}_{2} \mathrm{~S}$ dao động từ 0,3 - 1,5ppm.

Condensate Thiên Ưng có khối lượng riêng ở $15^{\circ} \mathrm{C}$ là 0,7743 $\mathrm{g} / \mathrm{mL}$ nên thuộc loại condensate trung bình so với các loại condensate đã từng khai thác trước đây tại Việt Nam. Hiệu suất phân đoạn naphtha trong condensate Thiên Ưng khá cao (61,39 \% khối lượng). Hàm lượng aromatic thuộc loại trung bình, mang đặc tính chung của dầu thô và condensate Việt Nam (hàm lượng lưu huỳnh, ni-tơ, nhựa và asphaltene đều thấp; hàm lượng kim loại vi lượng nickel, vanadium rất thấp).

Kết quả nghiên cứu này bổ sung vào hệ thống cơ sở dữ liệu tính chất dầu khí Việt Nam, từ đó giúp lựa chọn, thiết kế công nghệ phù hợp để khai thác, sử dụng hiệu quả tài nguyên dầu khí trong nước.

Từ khóa: Khí, condensate, tỷ trọng, hàm lượng paraffin rắn, mỏ Thiên Ưng, bể Nam Côn Sơn.

\section{Giới thiệu}

Mỏ Thiên Ưng thuộc Lô 04-3, bể Nam Côn Sơn, ở phía Đông Nam mỏ Bạch Hổ, nơi có độ sâu 120 m nước, cách bờ 270 km. Lô 04-3 được Chính phủ giao cho tổ hợp nhà thầu gồm Tập đoàn Dầu khí Việt Nam và Zarubezhneft (Liên bang Nga).

Vào 23 giờ 30 phút ngày 6/12/2016, Liên doanh Việt Nga "Vietsovpetro" đã hoàn thành khoan và mở vỉa thành công, đón dòng khí và condensate đầu tiên từ giếng khai thác TU-6, giàn BK-TNG mỏ Thiên Ưng. Sản lượng khai thác của mỏ Thiên Ưng trong giai đoạn 2017 - 2020 được trình bày trong Bảng 1.

Ngày nhận bài: 17/3/2021. Ngày phản biện đánh giá và sửa chữa: 17/3 - 8/7/2021. Ngày bài báo được duyệt đăng: 12/8/2021

\section{Phương pháp nghiên cứu}

\subsection{Lấy mẫu}

Do thiết kế giàn đầu giếng WHP - Thiên Ưng có bình tách cao áp, do đó dòng 3 pha (khí, condensate và nước) từ giếng khai thác sẽ được đưa vào bình tách cao áp, tại đây khí sẽ được tách riêng ra theo đường ống phía trên của bình tách cao áp, vị trí điểm lấy mẫu khí ngay sau bình tách, trước khi dòng khí được đưa qua hệ thống làm khô khí. Mẫu khí của mỏ Thiên Ưng sẽ được lấy tại giàn đầu giếng Thiên Ưng, theo tiêu chuẩn ASTM D 1145. Điều kiện lấy mẫu và sơ đồ vị trí lấy mẫu khí mỏ Thiên Ưng được thể hiện ở Bảng 2 và Hình 1.

Cũng giống như đối với mẫu khí, mẫu condensate cũng được lấy trên đường ra cho condensate sau bình tách cao áp. Áp suất bình tách từ 31,9 - 32,5 barg và nhiệt độ từ 44,8 - $46^{\circ} \mathrm{C}$. Sơ đồ vị trí lấy mẫu condensate mỏ Thiên Ưng được thể hiện trên Hình 1. 
Bảng 1. Sản lượng khai thác từ năm 2017 - 2019 và dự báo năm 2020

\begin{tabular}{|c|c|c|c|}
\hline Năm & Khí $\left(\mathbf{m}^{\mathbf{3}}\right)$ & Condensate $\left(\mathbf{m}^{\mathbf{3}}\right)$ & \multicolumn{1}{|c|}{ Ghi chú } \\
\hline 2017 & 114.413 .014 & 48.395 & \multirow{2}{*}{ Trích báo cáo Kế hoạch sản xuất kinh doanh của PV GAS. } \\
\hline 2018 & 139.363 .543 & 52.169 & \\
\hline 2019 & 115.131 .306 & 35.659 & 32.500 \\
\hline 2020 & 140.210 .243 & 300 \\
\hline
\end{tabular}

Bảng 2. Điều kiện, vị trí lấy mẫu mỏ Thiên Úng

\begin{tabular}{|c|c|c|c|c|c|}
\hline TT & Tên mẫu & Vị trí lấy mẫu & Thời điểm lấy mẫu & Áp suất (barg) & Nhiệt độ ( $\left.{ }^{\circ} \mathbf{C}\right)$ \\
\hline 1 & TU-1 & Sau bình tách cao áp & $8 / 2019$ & 31,9 & 45,2 \\
\hline 2 & TU-2 & Sau bình tách cao áp & $9 / 2019$ & 32,5 & 46 \\
\hline 3 & TU-3 & Sau bình tách cao áp & $10 / 2019$ & 32,1 & 45,8 \\
\hline 4 & TU-4 & Sau bình tách cao áp & $11 / 2019$ & 32 & 44,8 \\
\hline
\end{tabular}

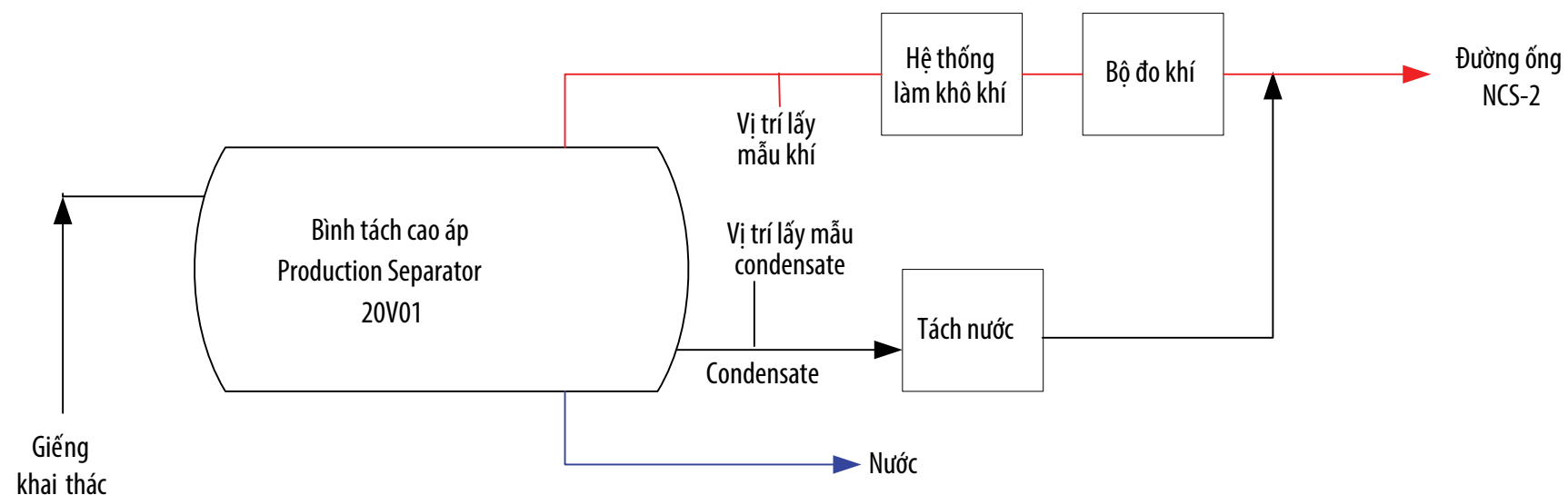

BK-TNG

Hình 1. Sơ đồ vị trí lấy mẫu condensate và khímỏ Thiên Ung.

Bảng 3. Danh mục các chỉ tiêu dùng cho phân tích mẫu khí

\begin{tabular}{|l|l|}
\hline \multicolumn{1}{|c|}{ Tiêu chuẩn } & Phương pháp \\
\hline Mẫu khí - thành phần hóa học & ASTM D 1945 \\
\hline Thành phần khí hydrocarbon $\mathrm{C}_{1}-\mathrm{C}_{12}$ & ASTM D 1945 \\
\hline Thành phần khí phi hydrocarbon $\left.\mathrm{O}_{2} ; \mathrm{CO}_{;} \mathrm{CO}_{2} ; \mathrm{H}_{2} ; \mathrm{N}_{2} ; \mathrm{He} ; \mathrm{Ar}\right)$ & \\
\hline Mẫu khí - tạp chất & ASTM D 5504 \\
\hline Hàm lượng sulfur oxide & ASTM D 5504 \\
\hline Hàm lượng $\mathrm{H}_{2} \mathrm{~S}$ & ASTM D 5504 \\
\hline Hàm lượng mercaptan và $\mathrm{COS}$ & ASTM D 5504 \\
\hline Tổng hàm lượng lưu huỳnh & ASTM D 5454 \\
\hline Hàm lượng hơi nước
\end{tabular}

Mẫu phân tích condensate mỏ Thiên Ưng do Vietsovpetro cung cấp. Mẫu được lấy ở áp suất khí quyển sau bình tách tại giàn Thiên Ưng và lấy làm 4 đợt như sau:

- Đợt 1: ngày 14/4/2019;

- Đợt 2: ngày 5/5/2019;

- Đợt 3: ngày 4/6/2019;
- Đợt 4: ngày 13/7/2019.

\subsection{Phương pháp phân tích}

Để phân tích các tính chất hóa lý của mẫu khí và condensate, nhóm tác giả đã sử dụng các tiêu chuẩn quốc tế (ASTM, UOP, ISO) và Việt Nam. Chi tiết các chỉ tiêu phân tích được trình bày trong Bảng 3 và 4. 
Bảng 4. Danh muc các chỉ tiêu dùng cho phân tích mẫu condensate

\begin{tabular}{|c|l|l|}
\hline TT & \multicolumn{1}{|c|}{ Tiêu chuẩn } & \multicolumn{1}{|c|}{ Phương pháp } \\
\hline 1 & Tỷ trọng & $\begin{array}{l}\text { ASTM D 1298-12b } \\
\text { ASTM D 5002-11 }\end{array}$ \\
\hline 2 & Điểm chảy & ASTM D 97-09 \\
\hline 3 & Độ nhớt động học & ASTM D 445-12 \\
\hline 4 & Tổng hàm lượng lưu huỳnh & ASTM D 4294-10 \\
\hline 5 & Khối lượng phân tử & Phương pháp nghiệm lạnh \\
\hline 6 & Hàm lượng paraffin rắn & UOP A 46-85 \\
\hline 7 & Hàm lượng ni-tơ & ASTM D 3228-08 \\
\hline 8 & Trị số acid & ASTM D 664-11a \\
\hline 9 & Hàm lượng nhựa & GOST 11858 \\
\hline 10 & Hàm lượng asphaltene & IP 143-04 \\
\hline 11 & Nhiệt lượng cháy & ASTM D 4809-18 \\
\hline 12 & Hàm lượng thủy ngân & UOP 938-10 \\
\hline 13 & Trị số octane & ASTM D 2699-18 \\
\hline
\end{tabular}

Bảng 5. Thành phân mẫu khímỏ Thiên U'ng

\begin{tabular}{|c|c|c|c|c|}
\hline TT & Thành phần & Phương pháp & Đơn vị & Giá trị \\
\hline 1 & $\mathrm{Ni}$-tơ & \multirow{12}{*}{ ASTM D 1945} & \multirow{12}{*}{$\% \mathrm{~mol}$} & 0,814 \\
\hline 2 & $\mathrm{CO}_{2}$ & & & 8,354 \\
\hline 3 & Methane & & & 76,111 \\
\hline 4 & Ethane & & & 7,1 \\
\hline 5 & Propane & & & 4,337 \\
\hline 6 & iso-butane & & & 1,005 \\
\hline 7 & n-butane & & & 1,13 \\
\hline 8 & neo-pentane & & & 0,005 \\
\hline 9 & iso-pentane & & & 0,39 \\
\hline 10 & n-pentane & & & 0,247 \\
\hline 11 & $\mathrm{H}_{2} \mathrm{~S}$ & & & 1 \\
\hline 12 & Tổng hàm lượng lưu huỳnh & & & 1 \\
\hline 13 & Hơi nước & ASTM D 5454 & $\mathrm{lb} / \mathrm{mmscf}$ & 46,6 \\
\hline 14 & Tổng hàm lượng thủy ngân & ASTM D 6350 & ppbV & 0,0576 \\
\hline
\end{tabular}

Bảng 6. Tính chất hóa lý mẫu khí mỏ Thiên Unng

\begin{tabular}{|c|l|c|c|c|}
\hline TT & \multicolumn{1}{|c|}{ Tính chất } & Phương pháp & Đơn vị & Giá trị \\
\hline 1 & Khối lượng riêng $\left(15^{\circ} \mathrm{C}, 1 \mathrm{~atm}\right)$ & ASTM D 3588 & $\mathrm{kg} / \mathrm{m}^{3}$ & 0,95 \\
\hline 2 & Tỷ trọng so với không khí $\left(15^{\circ} \mathrm{C}, 1 \mathrm{~atm}\right)$ & ASTM D 3588 & & 0,7752 \\
\hline 3 & Khối lượng phân tử & ASTM D 3588 & $\mathrm{kg} / \mathrm{kmol}$ & 22,4 \\
\hline 4 & Nhiệt cháy cao & ASTM D 3588 & $\mathrm{MJ} / \mathrm{m}^{3}$ & 42 \\
\hline 5 & Nhiệt cháy thấp & ASTM D 3588 & $\mathrm{MJ} / \mathrm{m}^{3}$ & 38,1 \\
\hline
\end{tabular}

Bảng 7. Các tính chất chung của condensate mỏ Thiên Ung

\begin{tabular}{|c|l|c|}
\hline TT & \multicolumn{1}{|c|}{ Chỉ tiêu phân tích } & Trung bình \\
\hline 1 & Khối lượng riêng ở $15^{\circ} \mathrm{C}(\mathrm{g} / \mathrm{mL})$ & 0,773 \\
\hline 2 & Điểm đông đặc/điểm chảy $\left({ }^{\circ} \mathrm{C}\right)$ & $-24 /-21$ \\
\hline 3 & Độ nhớt ở $40^{\circ} \mathrm{C}(\mathrm{cSt})$ & 0,808 \\
\hline 4 & Tổng hàm lượng lưu huỳnh $(\%$ khối lượng) & 0,0113 \\
\hline 5 & Khối lượng phân tử & 135,89 \\
\hline 6 & Hàm lượng paraffin rắn (\% khối lượng) & 2,31 \\
\hline 7 & Hàm lượng ni-tơ (\% khối lượng) & 0,006 \\
\hline 8 & Áp suất hơi bão hòa (psi) & 7,36 \\
\hline 9 & Hàm lượng nhựa (\% khối lượng) & 0,12 \\
\hline 10 & Hàm lượng asphaltene (\% khối lượng) & $<0,05$ \\
\hline 11 & Nhiệt lượng cháy trên $(\mathrm{kcal} / \mathrm{kg})$ & 11.034 \\
\hline & Nhiệt lượng cháy dưới $(\mathrm{kcal} / \mathrm{kg})$ & 10.319 \\
\hline
\end{tabular}

3. Kết quả phân tích thành phần, tính chất sản phẩm khí và condensate mỏ Thiên Ưng

\subsection{Tính chất khí mỏ Thiên Úng}

Kết quả trung bình thành phần và tính chất hóa lý của mẫu khí mỏ Thiên Ung được trình bày trong Bảng 5 và 6 .

\subsection{Tính chất condensate mỏ Thiên Ung}

Tính chất chung của mẫu condensate mỏ Thiên Ưng được trình bày trong Bảng 7.

Kết quả chưng cất đường cong điểm sôi thực theo ASTM D 2892 được trình bày trong Bảng 8.

Đặc điểm condensate mỏ Thiên Ưng là condensate trung bình, hiệu suất chiếm đa số chủ yếu ở phân đoạn xăng có nhiệt độ sôi đến $180^{\circ} \mathrm{C}$. Vi vậy, nhóm tác giả lựa chọn trình bày chi tiết tính chất đặc trưng của phân đoạn này trong Bảng 9.

\section{So sánh tính chất sản phẩm khí, condensate mỏ Thiên Ưng với các mỏ khác ở Việt Nam}

\subsection{So sánh tính chất khí}

\subsubsection{Hàm lượng methane}

Trong thời gian khảo sát (khoảng 4 tháng), thành phần khí mỏ Thiên Ung không thay đổi nhiều. Hàm lượng methane trong khí đồng hành mỏThiên Ưng là 76,111 \%mol, so với khí các mỏ thu gom bằng hệ thống đường ống Bạch Hổ - Dinh Cố thì khí Thiên Ưng có hàm lượng methane ở mức trung bình. Do là mỏ khí - condensate, nên các cấu tử nặng hơn methane trong khí như ethane, $\mathrm{C}_{3}-\mathrm{C}_{4^{\prime}} \mathrm{C}_{5^{\prime}} \mathrm{C}_{6}+$ cũng ở mức thấp so với các khí thu gom vào đường ống Bạch Hổ - Dinh Cố (Hình 3 và 4).

\subsubsection{Hàm lượng khí trơ}

Thành phần khí trơ của mỏ Thiên Ưng chỉ chứa ni-tơ với hàm lượng $0,814 \% \mathrm{~mol}$. So với các khí được thu gom bằng đường ống Bạch Hổ - Dinh Cố, khí đồng hành mỏ Thiên Ưng có hàm lượng khí trơ ở mức 
Bảng 8. Số liệu chưng cất điểm sôi thực theo ASTM D 2892

\begin{tabular}{|c|c|c|c|c|c|}
\hline TT & $\begin{array}{l}\text { Nhiệt độ cất } \\
\left({ }^{\circ} \mathrm{C}\right)\end{array}$ & $\begin{array}{c}\text { Tỷ lệ khối lượng cộng dồn } \\
(\%)\end{array}$ & Tỷ trọng d ${ }_{4}^{15}$ & $\begin{array}{l}\text { Tỷ lệ thể tích cộng dồn } \\
(\%)\end{array}$ & ${ }^{\circ} \mathrm{API}$ \\
\hline 1 & C1-C4 & 1,57 & 0,5875 & 2,08 & 109,1 \\
\hline 2 & 60 & 7,36 & 0,6391 & 9,20 & 89,9 \\
\hline 3 & 80 & 16,94 & 0,7178 & 19,69 & 65,6 \\
\hline 4 & 100 & 25,70 & 0,7529 & 28,85 & 56,4 \\
\hline 5 & 120 & 39,65 & 0,7746 & 43,01 & 51,1 \\
\hline 6 & 140 & 48 & 0,7774 & 51,46 & 50,5 \\
\hline 7 & 160 & 56,10 & 0,7991 & 59,31 & 45,5 \\
\hline 8 & 180 & 62,97 & 0,8011 & 65,95 & 45 \\
\hline 9 & 190 & 65,35 & 0,8037 & 68,24 & 44,5 \\
\hline 10 & 210 & 70,42 & 0,8177 & 73,04 & 41,5 \\
\hline 11 & 230 & 75,26 & 0,8255 & 77,58 & 39,8 \\
\hline 12 & $>230$ & 100 & 0,8545 & 100 & 34 \\
\hline
\end{tabular}

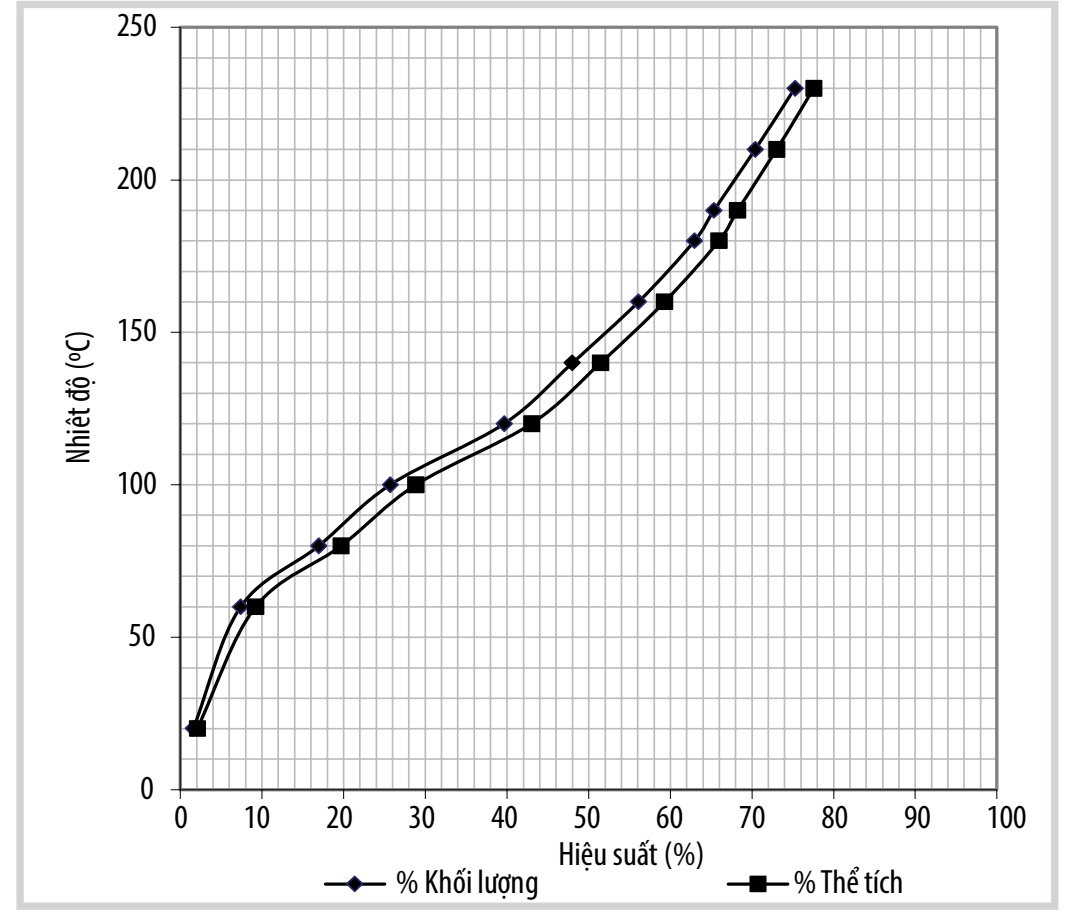

Hinh 2. Eường cong chưng cất điểm sôi thực condensate mỏ Thiên Ưng. Bảng 9. Tính chất của phân đoạn $\left(T_{s t^{-}}-180^{\circ} \mathrm{C}\right)$

\begin{tabular}{|c|l|c|}
\hline TT & \multicolumn{1}{|c|}{ Chỉ tiêu phân tích } & Kết quả \\
\hline 1 & $\begin{array}{l}\text { Hiệu suất phân đoạn (\% khối lượng) } \\
\text { (\% thể tích) }\end{array}$ & 61,39 \\
& Khối lượng riêng ở $15^{\circ} \mathrm{C}(\mathrm{g} / \mathrm{mL})$ & 63,87 \\
\hline \multirow{2}{*}{2} & Tỷ trọng ( $\left.\mathrm{d}_{60}^{60} \mathrm{~F}\right)$ & 0,7542 \\
& Tỷ trọng ( $\left.{ }^{\circ} \mathrm{API}\right)$ & 0,7545 \\
\hline 3 & Tổng hàm lượng lưu huỳnh $(\%$ khối lượng) & 56,04 \\
\hline 4 & Hàm lượng ni-tơ (\% khối lượng) & 0,0003 \\
\hline 5 & Áp suất hơi bão hòa (psi) & 0,0009 \\
\hline 6 & Trị số acid (mgKOH/g) & 3,42 \\
\hline 7 & Trị số octane RON & 0,036 \\
\hline & & 70 \\
\hline
\end{tabular}

trung bình của bể Cửu Long; khí các mỏ Sư Tử thuộc Lô 15-1 (Cửu Long JOC quản lý) có hàm lượng khí trơ cao hơn phần lớn các mỏ còn lại (Hình 5).

\subsubsection{Hàm lượng hơi nước}

Hàm lượng hơi nước đo được trong khí đồng hành mỏ Thiên Ưng, mẫu lấy sau bình tách cao áp từ $35,6-56,5 \mathrm{lb} / \mathrm{mmscf}$. So với tiêu chuẩn khí vận chuyển bằng đường ống, hàm lượng nước trong khí Thiên Ưng là cao $(<7 \mathrm{lb} / \mathrm{mmscf})$, tuy nhiên trên giàn Thiên Ưng có hệ thống làm khô khí trước khi vận chuyển bằng đường ống nên vẫn đảm bảo yêu cầu.

\subsubsection{Hàm lượng $\mathrm{H}_{2} \mathrm{~S}$ và $\mathrm{CO}_{2}$}

Hàm lượng $\mathrm{H}_{2} \mathrm{~S}$ và $\mathrm{CO}_{2}$ của khí Thiên Ung được thể hiện trong Bảng 10. Khi so sánh với khí từ các mỏ khí - condensate khác, khí Thiên Ưng có hàm lượng $\mathrm{CO}_{2} \mathrm{caO}$ hơn nhiều mỏ và hàm lượng $\mathrm{H}_{2} \mathrm{~S}$ gần thấp nhất trong các mỏ.

Qua 4 lần lấy mẫu, hàm lượng khí $\mathrm{H}_{2} \mathrm{~S}$ đo được trong khí mỏ Thiên Ưng dao động từ $0,3-1,5$ ppmV, trung bình bằng 1 ppmV. So với các mỏ được thu gom bằng hệ thống đường ống Bạch Hổ - Dinh Cố thì hàm lượng $\mathrm{H}_{2} \mathrm{~S}$ của khí mỏ Thiên Unng ở mức thấp.

Hàm lượng $\mathrm{CO}_{2}$ trong khí đồng hành mỏ Thiên Ưng là $8,354 \% \mathrm{~mol}$, đường ống khí Nam Côn Sơn 2 - giai đoạn 1 hiện nay 


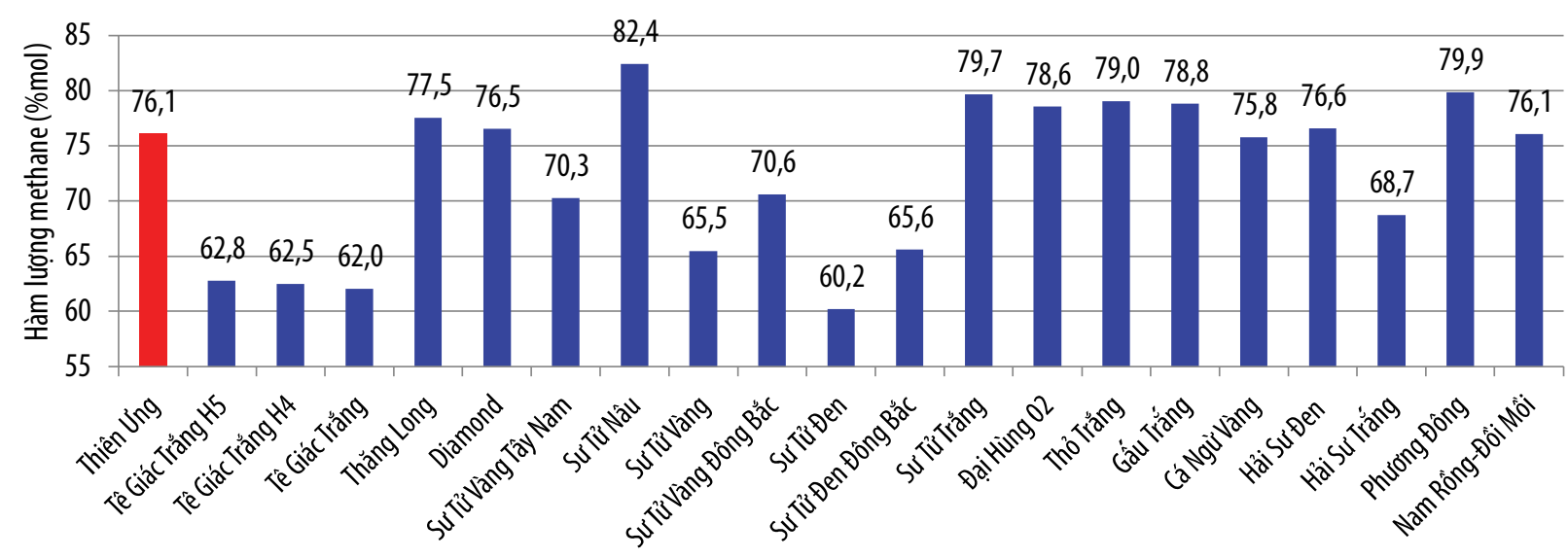

Hình 3. Hàm lượng methane trong khí các mỏ thu gom bằng đường ống Bạch Hổ - Dinh Cố.

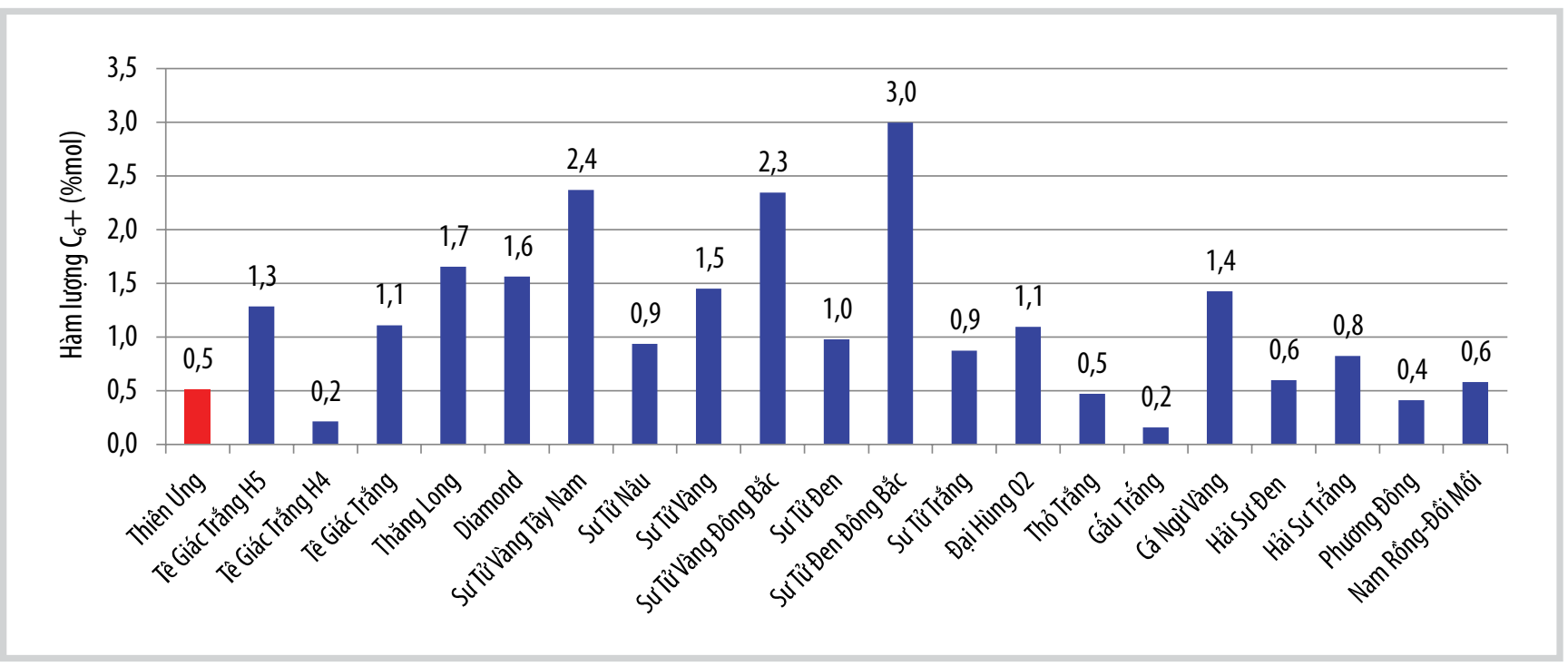

Hình 4. Hàm lượng $C_{6}+$ trong khí các mỏ thu gom bằng đường ống Bạch Hổ - Dinh Cố.
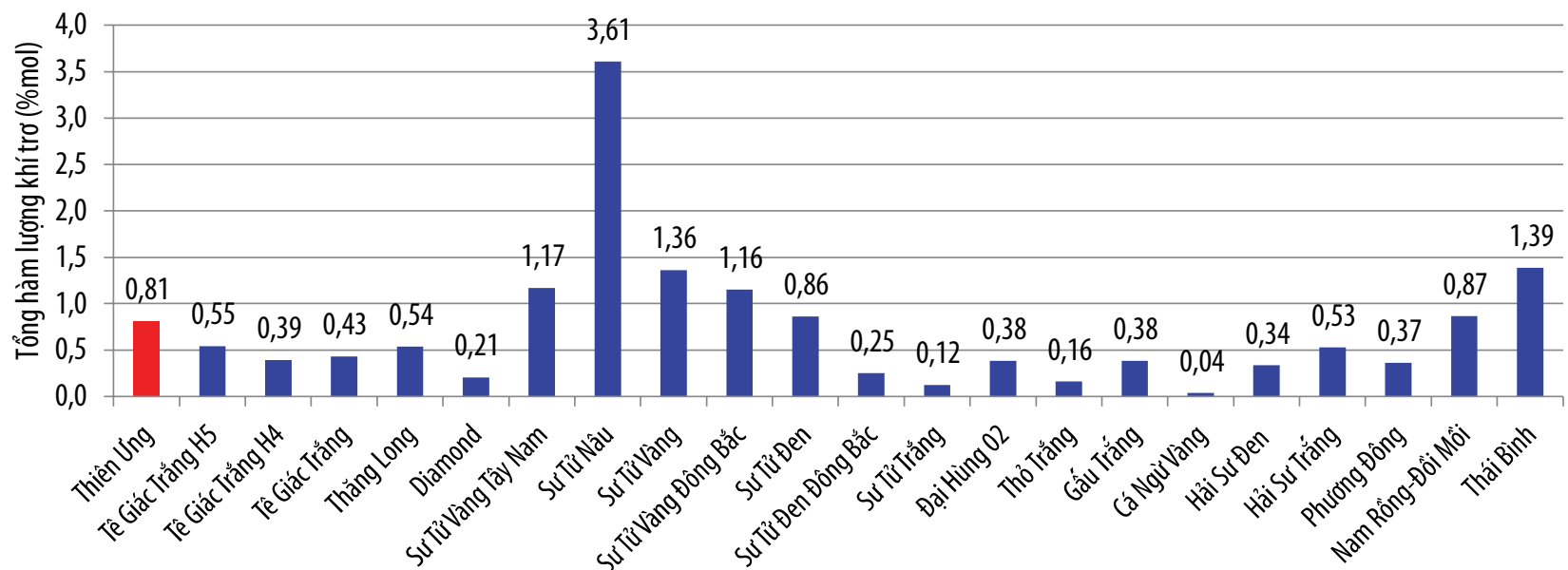

Hình 5. Hàm lượng khí trơ trong khí các mỏ được thu gom vào đường ống Bạch Hổ - Dinh Cố. 
Bảng 10. Thành phân $\mathrm{H}_{2} \mathrm{~S}$ và $\mathrm{CO}_{2}$ trong khí mỏ Thiên Ung

\begin{tabular}{|c|c|c|c|c|}
\hline Thành phần & Đơn vị & Giá trị nhỏ nhất & Giá trị lớn nhất & Trung bình \\
\hline $\mathrm{CO}_{2}$ & $\% \mathrm{~mol}$ & 8,009 & 8,780 & 8,354 \\
\hline $\mathrm{H}_{2} \mathrm{~S}$ & $\mathrm{ppmV}$ & 0,3 & 1,5 & 1 \\
\hline
\end{tabular}

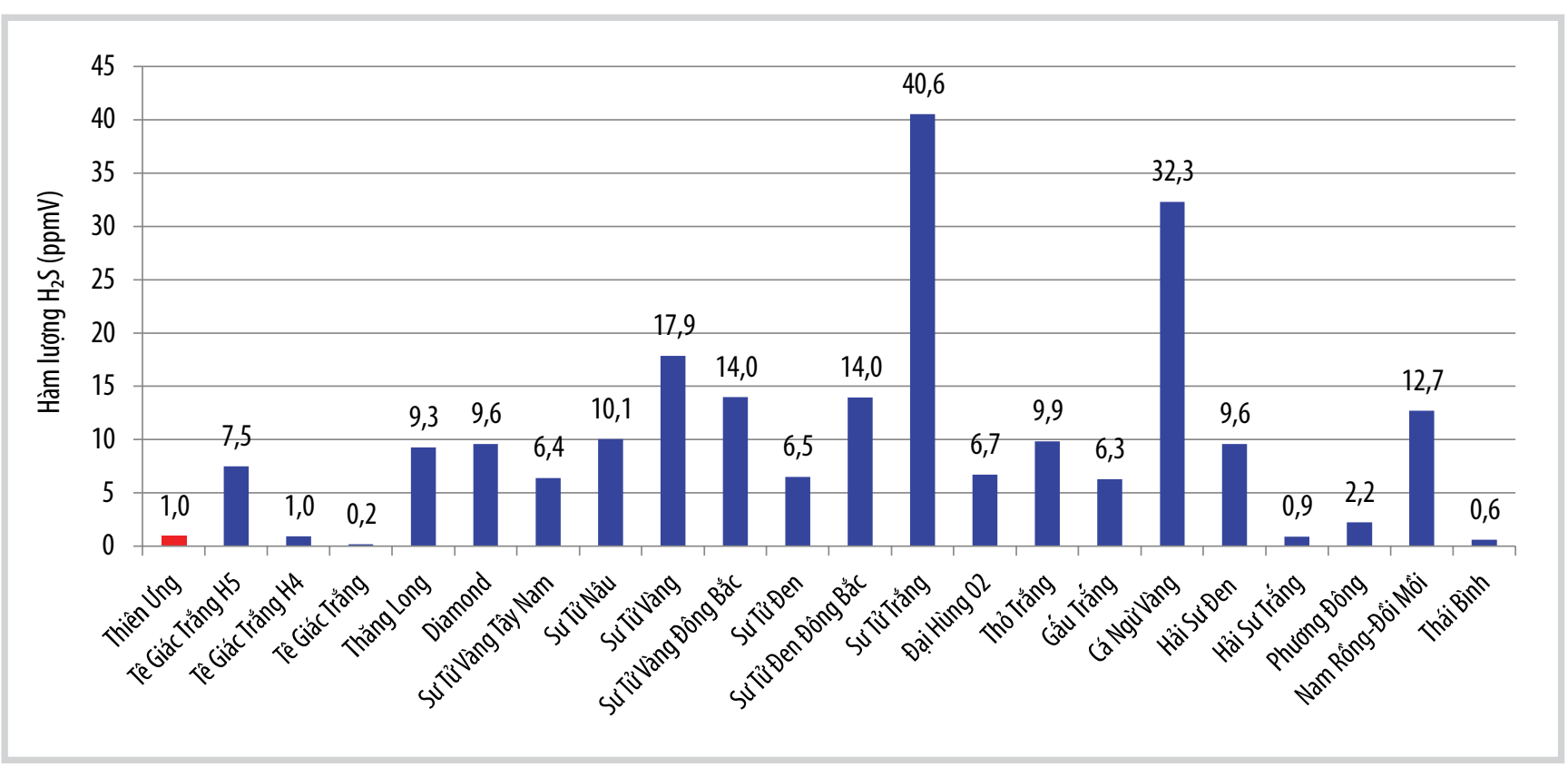

Hình 6. Hàm lượng khí H, Strong khí các mỏ thu gom bằng đường ống Bạch Hổ - Dinh Cố.

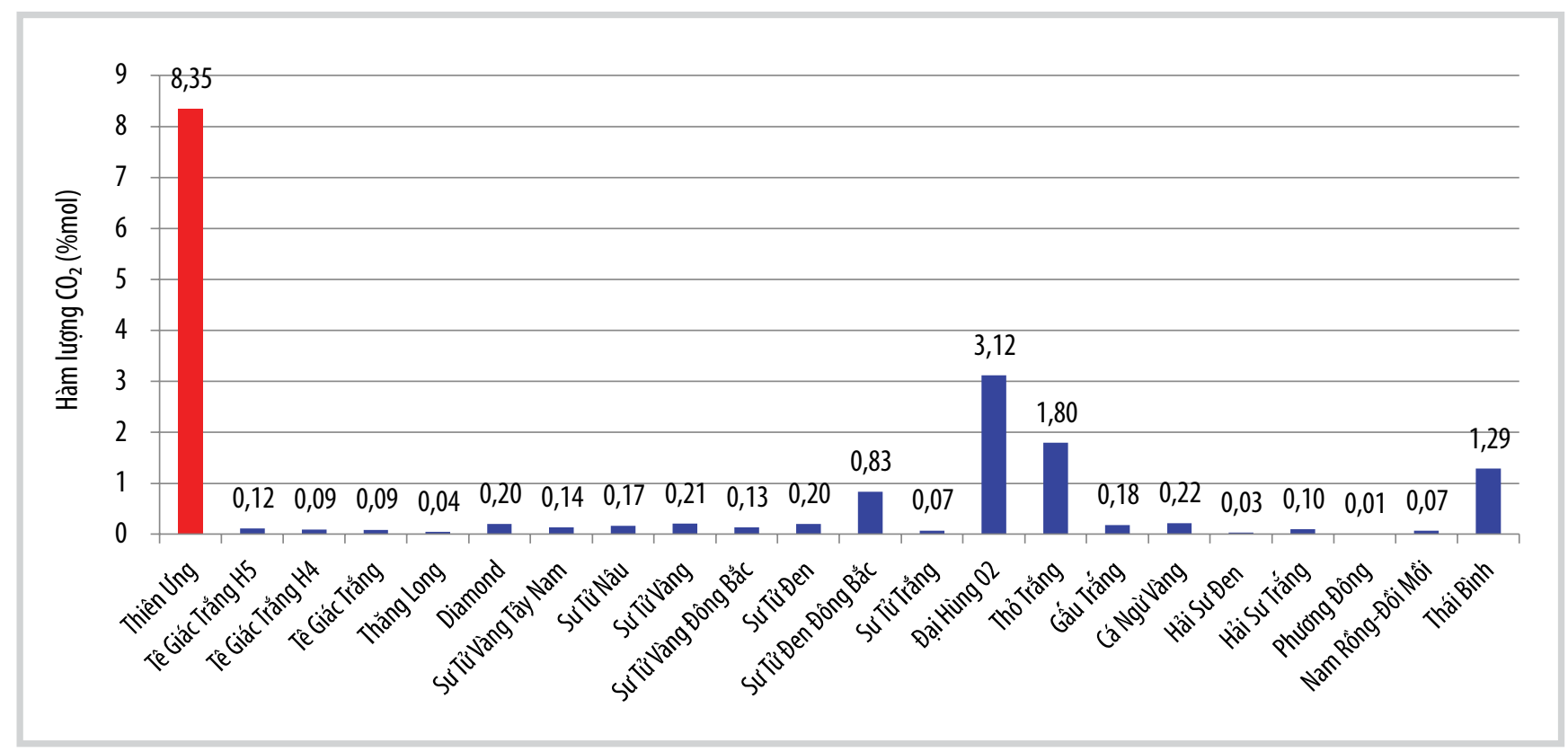

Hình 7. Hàm lượng khí CO trong khí các mỏ thu gom bằng đường ống Bạch Hổ - Dinh Cố.

đang thu gom khí mỏ Thiên Ưng và Đại Hùng, đều có hàm lượng $\mathrm{CO}_{2}$ cao (mỏ Đại Hùng có $\mathrm{CO}_{2}>3 \% \mathrm{~mol}$ ). Hệ thống đường ống Bạch Hổ - Dinh Cố, được đưa vào vận hành từ năm 1995, đến nay đã hoạt động 20 năm. Theo yêu cầu từ PV GAS, để đảm bảo an toàn vận hành, tất cả các nguồn khí khi đưa vào đường ống, cần phải đảm bảo hàm lượng $\mathrm{CO}_{2}$ sau quá trình hòa trộn không vượt quá giới hạn 1 \%mol. Việc kiểm soát lưu lượng khai thác để hàm lượng $\mathrm{CO}_{2}$ trong đường ống khí về trong giới hạn là hết sức quan trọng để vận hành an toàn đường ống. 


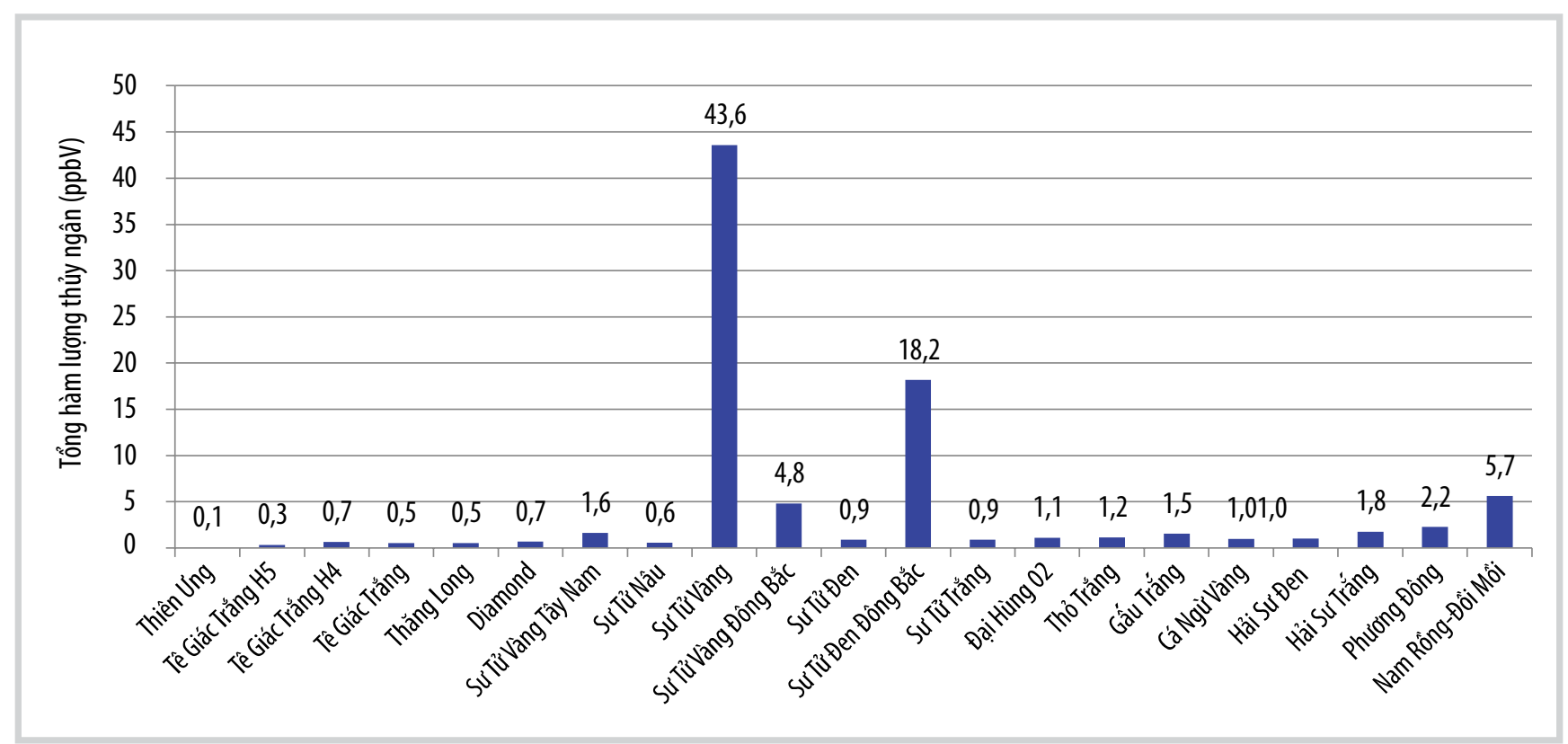

Hình 8. Hàm lượng khí thủy ngân trong khí các mỏ thu gom bằng đường ống Bạch Hổ - Dinh Cố.

\subsubsection{Hàm lượng thủy ngân}

Hàm lượng thủy ngân trong khí mỏ Thiên Ưng là 0,06 ppbV thấp nhất trong các khí thu gom vào đường ống Bạch Hổ - Dinh Cố. Tham khảo các hợp đồng thu gom, vận chuyển khí của các mỏ trong bể Cửu Long hiện tại thì mức thủy ngân này hoàn toàn đáp ứng yêu cầu ( $<5$ ppbV).

Khí mỏ Thiên Ưng có hàm lượng tạp chất như $\mathrm{H}_{2} \mathrm{~S}$ và thủy ngân thấp, tổng thành phần hydrocarbon chiếm trên 90 \%mol. Nhiệt trị tuy không cao nhưng đáp ứng yêu cầu khi so sánh với các hợp đồng thu gom khí của các mỏ trong bể Cửu Long. Với chất lượng khí như vậy, việc thu gom khí Thiên Ưng đưa về bờ chế biến và sử dụng đã góp phần vào việc gia tăng sản lượng và đảm bảo an ninh năng lượng quốc gia. Tuy nhiên, do có hàm lượng $\mathrm{CO}_{2}$ cao, việc vận hành sản xuất cần có các lưu ý đặc biệt về vấn đề ăn mòn đường ống nội mỏ và cần kiểm soát lưu lượng khai thác để hàm lượng $\mathrm{CO}_{2}$ trong khí chung của hệ thống đường ống Bạch Hổ - Dinh Cố phải thấp hơn $1 \% \mathrm{~mol}$, đáp ứng yêu cầu về an toàn đường ống.

\subsection{So sánh tính chất cơ bản của condensate Thiên Úng với các loại condensate khác tại Việt Nam}

Kết quả so sánh tỷ trọng và hàm lượng paraffin rắn của condensate Thiên Ưng với các loại condensate khác tại Việt Nam được thể hiện trong Hình 9 và 10.

Tỷ trọng của các loại condensate nằm trong khoảng từ $0,74-0,82 \mathrm{~g} / \mathrm{mL}$ (Hình 10). Như vậy, condensate có tỷ trọng nhỏ nhất trong số các condensate đã phân tích là condensate Lan Tây $(0,7491 \mathrm{~g} / \mathrm{mL})$, tiếp đến là condensate Thái Bình $(0,7516 \mathrm{~g} / \mathrm{mL})$ và nặng nhất là condensate Mộc Tinh $(0,8291 \mathrm{~g} / \mathrm{mL})$. Do có sự khác biệt khá lớn về tỷ trọng nên giá trị khối lượng phân tử của các loại condensate này cũng chênh lệch lớn. Theo các phân tích trước và gần đây cho thấy condensate Lan Tây và condensate Thiên Ung khi chưng cất sẽ thu được chủ yếu là các phân đoạn naphtha với hiệu suất cao và chỉ chưng cất được đến nhiệt độ sôi cuối khoảng $230^{\circ} \mathrm{C}$; còn đối với condensate Mộc Tinh, ngoài việc thu được các phân đoạn naphtha với hiệu suất trung bình còn thu được phân đoạn gas oil với hiệu suất khá cao và chưng cất được đến nhiệt độ sôi cuối là $360^{\circ} \mathrm{C}$.

Hàm lượng paraffin rắn của condensate Thiên Ung thấp $(2,14 \%$ khối lượng) dẫn đến điểm chảy của condensate Thiên Ung khá thấp $-21^{\circ} \mathrm{C}$. Trong khi đó, hàm lượng paraffin rắn của một số condensate khác tại Việt Nam như condensate Mộc Tinh (10,82 \% khối lượng), condensate Hải Thạch (10,95 \% khối lượng) và condensate Sư Tử Trắng (13,36 \% khối lượng) cao, với điểm chảy tương ứng là $12^{\circ} \mathrm{C}, 27^{\circ} \mathrm{C}$ và $18^{\circ} \mathrm{C}$. Trong khi nhiệt độ vùng cận đáy biển Việt Nam trong khu vực có các mỏ dầu khí dao động từ $22-28^{\circ} \mathrm{C}$ [1], thấp hơn từ $5-10^{\circ} \mathrm{C}$ so với nhiệt độ đông đặc của condensate có điểm chảy cao $\left(27^{\circ} \mathrm{C}\right)$, điều này có thể gây ra hiện tượng lắng đọng paraffin làm tắc nghẽn đường ống trong quá trình khai thác và vận chuyển. 


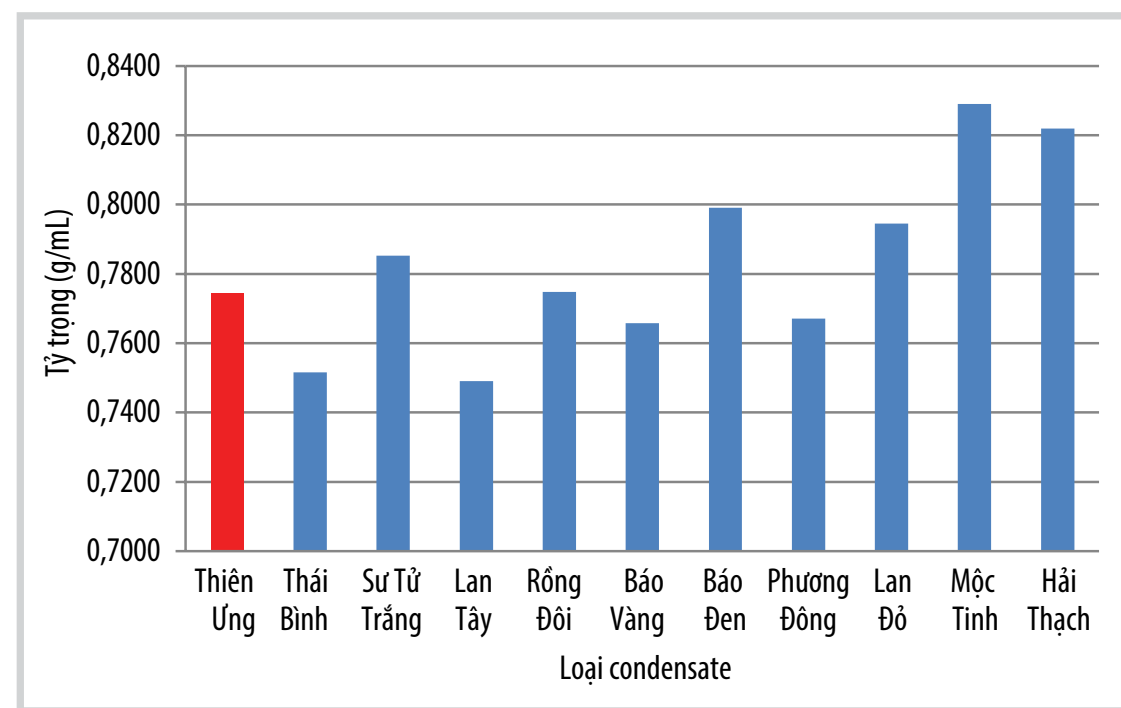

Hình 9. Tỷ trọng của các loại condensate tại Việt Nam.

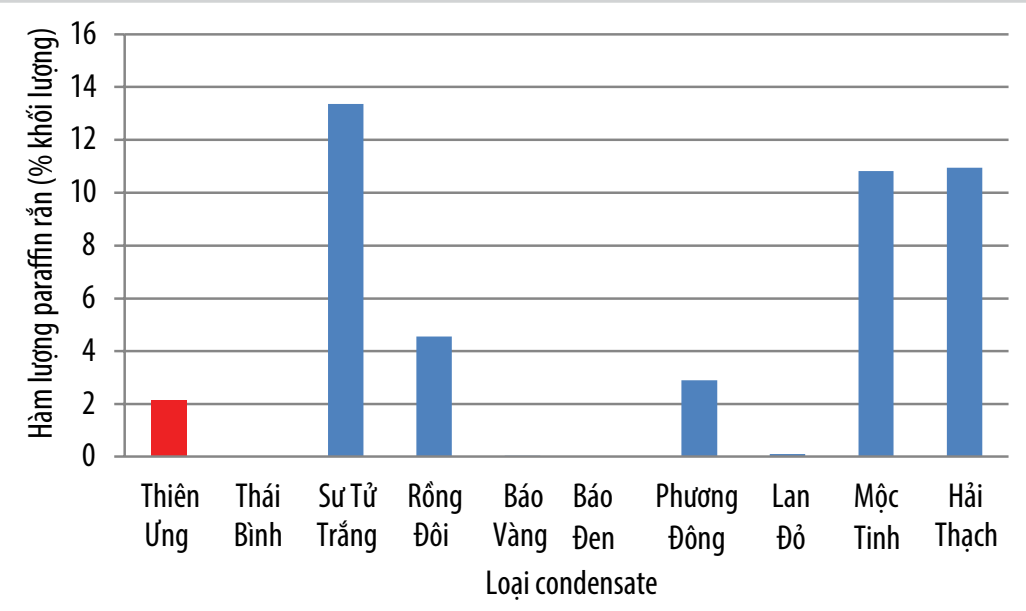

Hình 10. Hàm lượng paraffin rắn của các loại condensate.

\section{Kết luận và kiến nghị}

Khí mỏ Thiên Ưng là khí tự nhiên có thành phần chủ yếu là methane với hàm lượng dao động từ 75,231 - 76,402 \%mol. Tổng các thành phần hydrocarbon còn lại $\left(C_{2}+\right)$ chiếm tỷ lệ thấp, từ $7,083-7,123 \%$ mol; hàm lượng hydrocarbon lỏng $\left(\mathrm{C}_{6}+\right)$ rất thấp, từ $0,172-0,226 \%$ mol. Khí Thiên Ung là khí ngọt do hàm lượng $\mathrm{H}_{2} \mathrm{~S}$ trong khí dao động từ $0,3-1,5 \mathrm{ppmV}$, trung bình bằng 1 ppmV.

So với khí các mỏ được thu gom bằng hệ thống đường ống Bạch Hổ Dinh Cố thì hàm lượng $\mathrm{H}_{2} \mathrm{~S}$ của khí mỏ Thiên Ưng ở mức thấp, ít tạp chất và ít khí phi hydrocarbon nên đây là khí có chất lượng tốt. Tuy nhiên, do tổng hàm lượng các thành phần khí có tính acid $\left(\mathrm{H}_{2} \mathrm{~S}+\mathrm{CO}_{2}\right)$ cao nên cần lưu ý xử lý loại khí này trước khi đưa vào vận chuyển và sử dụng.

Hàm lượng hơi nước đo được trong khí đồng hành mỏ Thiên Ưng, mẫu lấy sau bình tách cao áp từ 35,6 - 56,5 lb/mmscf. So với tiêu chuẩn khí vận chuyển bằng đường ống ( $<7 \mathrm{lb} / \mathrm{mmscf}$ ), hàm lượng hơi nước trong khí Thiên Ung là cao, tuy nhiên trên giàn Thiên Ưng có hệ thống làm khô khí trước khi vận chuyển bằng đường ống nên vẫn đảm bảo yêu cầu.

Theo phân loại về khối lượng, condensate Thiên Ưng có khối lượng riêng ở $15{ }^{\circ} \mathrm{C}$ là $0,7743 \mathrm{~g} / \mathrm{mL}$ nên thuộc condensate trung bình so với các mỏ condensate đã từng khai thác trước đây tại Việt Nam; có hiệu suất phân đoạn naphtha cao $(61,39 \%$ khối lượng), có hàm lượng aromatic thuộc loại trung bình, mang đặc tính chung của dầu thô và condensate Việt Nam đó là hàm lượng lưu huỳnh, hàm lượng ni-tơ, hàm lượng nhựa và hàm lượng asphaltene đều thấp, kim loại vi lượng nickel, vanadium cũng rất thấp. Tuy nhiên, condensate mỏ Thiên Unng không phù hợp để phối trộn làm nguyên liệu cho Nhà máy Lọc dầu Dung Quất với tỷ lệ lớn, do tỷ trọng của condensate này thấp. Condensate Thiên Ưng có thể sử dụng để phối trộn với xăng reformate của nhà máy lọc có trị số octane cao để sản xuất xăng thương mại.

Phân đoạn $\mathrm{T}_{\text {sđ }}-180^{\circ} \mathrm{C}$, có hiệu suất vào loại cao (61,39 \% khối lượng), hàm lượng $n$-paraffin cần để chuyển hóa thành iso-paraffin chiếm tỷ lệ thấp, 18,08 \% khối lượng, trong khi đó hàm lượng iso-paraffin chiếm tỷ lệ cao hơn là 27,28 \% khối lượng. Do đó phân đoạn này cũng không phù hợp để làm nguyên liệu cho Phân xưởng ISOM [2]. Do hàm lượng lưu huỳnh thấp $(0,0003 \%$ khối lượng - 3 ppm) nên có thể sử dụng làm nguyên liệu cho cụm phân xưởng NHT - CCR [3].

Phân đoạn này có trị số octane thấp (70), tuy nhiên vẫn có thể pha xăng trực tiếp với tỷ lệ phối trộn phù hợp.

Nhìn chung, các loại condensate đã khai thác và thương mại hóa từ trước cho đến nay tại Việt Nam có hàm lượng lưu huỳnh, hàm lượng ni-tơ, hàm lượng nhựa và asphaltene thấp. 
Đây là đặc điểm thuận lợi trong khai thác, vận chuyển và chế biến condensate tại Việt Nam.

\section{Tài liệu tham khảo}

[1] Đào Thị Hải Hà, Hoàng Linh và Lương Văn Tuyên, “Tổng hợp phụ gia giảm nhiệt độ đông đặc cho dầu thô nhiều parafin mỏ Bạch Hổ trong quá trình khai thác và vận chuyển trên nền ester của poly - triethanolamine", Tạp chí Dâu khí, Số 5, trang 26 - 35, 2013.
[2] Đinh Thị Quỳnh Như và nnk, "Xây dựng danh mục các chỉ tiêu phân tích dâu thô phục vụ xây dựng dữ liệu cơ sở”, Viện Dâuu khí Việt Nam, 2005.

[3] Trịnh Ngọc Trung và nnk, "Nghiên cứu khả năng bổ sung nguyên liệu naphtha nặng cho cụm CCR của Nhà máy Lọc dâu Dung Quất để đáp ứng tối đa công suất phân xưởng CCR và tăng trị số octan cho xăng", Viện Dầu khí Việt Nam, 2009.

\title{
ANALYSING THE COMPOSITION AND PROPERTIES OF GAS AND CONDENSATE PRODUCTS OF THIEN UNG FIELD
}

\author{
Nguyen Ba Khoa, Nguyen Huynh Anh, Nguyen Phan Tri, Nguyen Thi Anh Thu, Nguyen Hien Phong, Nguyen Xuan Hop, Ngo Thi Loan \\ Luong Thi Hong Hai, Nguyen Van Lam, Nguyen Thanh Tung, Nguyen Van Hung, Truong Huu Dang Khoi \\ Vietnam Petroleum Institute \\ Email: anhnguyenh@vpi.pvn.vn
}

\section{Summary}

The article presents the analysis results for the composition and properties of gas and condensate samples collected from Thien Ung field, as compared with the properties of other gas and condensate products in Vietnam. The largest component of natural gas from Thien Ung field is methane with the content ranging from 75.231 to $76.402 \%$ mol. The remaining hydrocarbon components in Thien Ung natural gas make up from 7.083 to $7.123 \% \mathrm{~mol}$, in which liquid hydrocarbon content $\left(\mathrm{C}_{6}+\right)$ is very low, from 0.172 to $0.226 \% \mathrm{~mol}$. Thien Ung natural gas is a sweet gas with $\mathrm{H}_{2} \mathrm{~S}$ content ranging from 0.3 to $1.5 \mathrm{ppm}$.

The density of Thien Ung condensate at $15^{\circ} \mathrm{C}$ is $0.7743 \mathrm{~g} / \mathrm{ml}$, so this is an average condensate compared to other condensates that have been produced in Vietnam. The mass yield of naphtha distillation cut from Thien Ung condensate is high (61.39\%mass). Aromatic hydrocarbon content is at average level with common characteristics of crude oils and condensates in Vietnam (low contents of sulfur, nitrogen, resin and asphaltene; trace metal nickel and vanadium contents are also very low).

The results of this study provide additional data to the Vietnam oil and gas properties database system, which will facilitate the selection and design of suitable technologies for effective extraction and use of the domestic oil and gas resources of Vietnam.

Key words: Gas, condensate, proportion, solid paraffin content, Thien Ung field, Nam Con Son basin. 